\title{
Multistage Multiattribute Group Decision-Making Method Based on Triangular Fuzzy MULTIMOORA
}

\author{
Wen-feng Dai, ${ }^{1,2}$ Qiu-yan Zhong, ${ }^{2}$ and Chun-ze Qi ${ }^{1}$ \\ ${ }^{1}$ School of Information Engineering, Lanzhou University of Finance and Economics, Lanzhou 730020, China \\ ${ }^{2}$ Faculty of Management and Economics, Dalian University of Technology, Dalian 116024, China \\ Correspondence should be addressed to Wen-feng Dai; hope2503@sina.com
}

Received 6 April 2016; Revised 26 June 2016; Accepted 3 July 2016

Academic Editor: Anna M. Gil-Lafuente

Copyright (c) 2016 Wen-feng Dai et al. This is an open access article distributed under the Creative Commons Attribution License, which permits unrestricted use, distribution, and reproduction in any medium, provided the original work is properly cited.

\begin{abstract}
This paper proposed a new multiattribute group decision-making method, in which the period significance coefficients and the attribute significance coefficients are completely unknown, and the attribute values are triangular fuzzy numbers. At first, to obtain the period significance coefficients, the period significance coefficients optimization model is constructed according to the time degree and the differences of the decision information in different periods. Then, attribute significance coefficients are determined by the maximum deviation method. Based on this, alternatives are ranked by the triangular fuzzy ratio system method, the triangular fuzzy reference point method, and the triangular fuzzy full multiplicative form, respectively. The dominance theory is used for aggregating the subordinate rankings into the final ranking. Finally, a numerical example is presented to illustrate the feasibility and effectiveness of the proposed method.
\end{abstract}

\section{Introduction}

Multiattribute decision-making (MADM) has been widely used in many practical problems, such as emergency plan selection, supplier selection, consumer purchasing selection, and human resource management. However, when dealing with many complex problems, single decision-maker cannot accurately consider all aspects of the decision problem, which will lead to unreasonable decision results. In this case, multiple decision-makers are required to participate in the decision process and the multiattribute group decision-making (MAGDM) appears. Nowadays, MAGDM has attracted many researchers' attention and has become a hot research topic [19].

In classical MAGDM methods, the evaluation values and the attribute significance coefficients are known completely. However, in the practical decision, they are partly known, even completely unknown. To deal with these problems, many fuzzy decision methods and stochastic decision methods are proposed. Parameters in fuzzy decision methods are usually assumed to have given membership functions. Similarly, parameters in the stochastic decision-making methods are presumed to have appointed probability distributions.
But decision-makers may not be capable of determining membership functions or probability distributions properly. So many decision methods based on the fuzzy logic theory are proposed. Cao et al. [10-12] presented decision methods based on interval numbers. However, when interval numbers are used to represent the decision information, the interval ranges of them are usually too large so as to cover the whole value range. The intervals are likely to be further enlarged after many operations [13-15]. In addition, each value between the upper and the lower bound of the interval number is generally considered to have the same value opportunity [16]. All these disadvantages will lead to the information distortion or deviation. Compared with interval numbers, triangular fuzzy numbers not only can represent the interval range of the decision information but can highlight the gravity center having the largest probability. Hence, the triangular number can make up the deficiency of the interval number in the precision and facilitate the decision-making at least to some extent.

The multiobjective optimization on the basis of ratio analysis (MOORA), a newly developed MADM method, was firstly proposed by Brauers and Zavadskas for solving MADM problems $[17,18]$. Then, MOORA was extended to 
MULTIMOORA (MOORA plus the full multiplicative form) [19-21]. Compared with other MADM methods, MULTIMOORA is easier to understand and implement. Besides, MULTIMOORA can facilitate the decision-making process and provide effective rankings [22-25]. At present, MULTIMOORA has been expanded into different forms according to the fuzzy logic theory. Brauers et al. [19] extended MULTIMOORA into the fuzzy number environment. Liu et al. [26] expanded MULTIMOORA based on the fuzzy number and used it to evaluate the risk of the failure mode. Baležentis et al. [27] presented a fuzzy MULTIMOORA method for linguistic reasoning and used it to deal with a candidate selection problem. Datta et al. [28] proposed greyMULTIMOORA and used it to solve the robot selection problem.

However, few studies extended MULTIMOORA into the triangular fuzzy number environment and obtained the final ranking by the dominance theory. Baležentis et al. [27] extended MULTIMOORA based on the triangular fuzzy number. But they only considered the current decision information and ignored the importance of the historical information. In addition, the attribute significance coefficients are given in advance, which will lead to unreasonable results. Based on this, we developed a novel extension of MULTIMOORA method based on considering the current and historical information to solve MAGDM problems. The major contribution of our proposed method is that it considered the current and the historical information of the decision object. So it can describe the decision object comprehensively and objectively. Besides, to obtain the stable period significance coefficients, the period significance coefficients optimization model is constructed according to the time degree and the differences of the decision information in different periods. Hence, our proposed method can help to obtain more objective decision results.

The remainder of this paper is organized as follows: Section 2 briefly introduces some basic concepts related to the triangular fuzzy number. Section 3 mainly presents the steps of the original MULTIMOORA method. A novel extension of MULTIMOORA is proposed in Section 4. In order to illustrate the feasibility and effectiveness of the proposed method, a numerical example is presented in Section 5. Finally, conclusions are given in Section 6.

\section{Triangular Fuzzy Numbers}

Compared with the crisp number, the triangular fuzzy number is more in accord with the uncertainty of the decision environment and the fuzziness of human thinking. Besides, compared with the interval number, the triangular fuzzy number not only can represent the interval range of the decision information but also can highlight the gravity center having the maximum value probability. Hence, the triangular number can reduce the information distortion and information deviation in the process of decision-making. Based on this, this paper represents the decision information with triangular fuzzy numbers.
Definition 1. A triangular fuzzy number $\tilde{a}$ is defined as $\left(a^{L}, a^{M}, a^{U}\right)$ and its membership function $\mu_{\tilde{a}}(x)$ can be defined as [28]

$$
\mu_{\tilde{a}}(x)= \begin{cases}\frac{\left(x-a^{L}\right)}{\left(a^{M}-a^{L}\right)} & a^{L} \leq x \leq a^{M}, \\ \frac{\left(a^{U}-x\right)}{\left(a^{U}-a^{M}\right)} & a^{M} \leq x \leq a^{U}, \\ 0 & \text { otherwise }\end{cases}
$$

in which $x \in R$ and $a^{L}$ and $a^{U}$ represent the lower bound and the upper bound of the triangular fuzzy number $\tilde{a}$, respectively, $0 \leq a^{L} \leq a^{M} \leq a^{U}$. If $a^{L}, a^{M}$, and $a^{U}$ are equal, $\tilde{a}$ degenerates a crisp value.

Definition 2. Let $\widetilde{a}=\left(a^{L}, a^{M}, a^{U}\right)$ and $\widetilde{b}=\left(b^{L}, b^{M}, b^{U}\right)$ be two triangular fuzzy numbers and let $\lambda$ be a real number; they follow the following rules $[29,30]$ :

(1) $\widetilde{a}+\widetilde{b}=\left(a^{L}+b^{L}, a^{M}+b^{M}, a^{U}+b^{U}\right)$.

(2) $\tilde{a} \times \tilde{b}=\left(a^{L} \times b^{L}, a^{M} \times b^{M}, a^{U} \times b^{U}\right)$.

(3) $\lambda \widetilde{a}=\left(\lambda a^{L}, \lambda a^{M}, \lambda a^{U}\right)$.

(4) $\tilde{a}^{\lambda}=\left(\left(a^{L}\right)^{\lambda},\left(a^{M}\right)^{\lambda},\left(a^{U}\right)^{\lambda}\right)$.

(5) $\tilde{b} / \tilde{a}=\left(b^{L} / a^{U}, b^{M} / a^{M}, b^{U} / a^{L}\right)$.

Definition 3. Let $\tilde{a}=\left(a^{L}, a^{M}, a^{U}\right)$ and $\widetilde{b}=\left(b^{L}, b^{M}, b^{U}\right)$ be two triangular fuzzy numbers; the distance between them could be obtained as the following:

$$
\begin{aligned}
& d(\tilde{a}, \tilde{b}) \\
& \quad=\sqrt{\frac{\left[\left(a^{L}-b^{L}\right)^{2}+\left(a^{M}-b^{M}\right)^{2}+\left(a^{U}-b^{U}\right)^{2}\right]}{3} .}
\end{aligned}
$$

Definition 4. Let $\widetilde{a}=\left(a^{L}, a^{M}, a^{U}\right)$ be a triangular fuzzy number; its defuzzy formula can be defined as the following:

$$
a=\frac{a^{L}+2 a^{M}+a^{U}}{4} .
$$

\section{The MULTIMOORA Method}

Brauers and Zavadskas extended the MOORA method to MULTIMOORA which includes three parts [17-19]: the ratio system method, the reference point method, and the full multiplicative form method.

Let $A=\left\{a_{1}, a_{2}, \ldots, a_{m}\right\}$ be the alternative set, let $C=$ $\left\{c_{1}, c_{2}, \ldots, c_{n}\right\}$ be the attribute set, let $V=\left(v_{i j}\right)_{m \times n}$ be the decision matrix, let $v_{i j}$ be the evaluation value of alternative $a_{i}$ under the attribute $c_{j}, i=1,2, \ldots, m, j=1,2, \ldots, n$, let $V^{*}=\left(v_{i j}^{*}\right)_{m \times n}$ be the standardized decision matrix, and let $v_{i j}^{*}$ be the standardized form of $v_{i j}$. Hence,

$$
v_{i j}^{*}=\frac{v_{i j}}{\sqrt{\sum_{i=1}^{m} v_{i j}^{2}}} .
$$


3.1. The Ratio System Method. The evaluation value of the alternative $a_{i}$ under the ratio system method can be defined as the following:

$$
y_{i}=\sum_{j=1}^{g} v_{i j}^{*}-\sum_{j=g+1}^{n} v_{i j}^{*}
$$

in which $g$ and $n-g$ represent the numbers of benefit attributes and cost attributes, respectively, $w_{j}$ represents the attribute significance coefficient, and $y_{i}$ represents the evaluation value of alternative $a_{i}$ under the ratio system method. Alternatives are sorted according to evaluation values in descending order. The optimal alternative is the one having the biggest value [13]:

$$
a_{\mathrm{RS}}^{*}=\left\{a_{i} \mid \max _{i} y_{i}\right\}
$$

3.2. The Reference Point Method. At first, the maximal attribute reference point should be specified by (7). Hence,

$$
r_{j}= \begin{cases}\max _{i} v_{i j}^{*}, & j \leq g, \\ \min _{i} v_{i j}^{*}, & j>g .\end{cases}
$$

The deviation between the standardized evaluation value $v_{i j}^{*}$ and the reference point $r_{j}$ can be defined as $\left|r_{j}-v_{i j}^{*}\right|$. So, the evaluation value of $i$ th alternative under the reference point method can be represented as the following:

$$
z_{i}=\max _{j}\left|r_{j}-v_{i j}^{*}\right|
$$

Obviously, the smaller $z_{i}$ is, the better alternative $a_{i}$ will be. The optimal alternative is the one having the smallest evaluation value. Hence,

$$
a_{\mathrm{RP}}^{*}=\left\{a_{i} \mid \min _{i} z_{i}\right\} .
$$

3.3. The Full Multiplicative Form Method. The evaluation value of the $i$ th alternative under the full multiplicative form can be defined as the following:

$$
U_{i}=\frac{\prod_{j=1}^{g} v_{i j}^{*}}{\prod_{j=g+1}^{n} v_{i j}^{*}}
$$

in which $\prod_{j=1}^{g} v_{i j}^{*}$ represents the product of all benefit attributes' normalized evaluation values and $\prod_{j=g+1}^{n} v_{i j}^{*}$ represents the product of all cost attributes' normalized evaluation values. The bigger $U_{i}$ is, the better $a_{i}$ will be. The optimal alternative can be specified by

$$
a_{\mathrm{MF}}^{*}=\left\{a_{i} \mid \max _{i} U_{i}\right\}
$$

3.4. The Final Ranking of MULTIMOORA. The dominance theory can integrate several rankings into a compressive ranking according to propositions like equability, transitivity and domination, and so forth. Hence, the alternative rankings obtained from Sections 3.1, 3.2, and 3.3 can be aggregated into the final ranking by the dominance theory. The dominance theory's application in MULTIMOORA is introduced in literatures $[7,8,20]$.

\section{The Proposed Method}

4.1. The Decision-Making Problem Description. Let $A=$ $\left\{a_{1}, a_{2}, \ldots, a_{m}\right\}$ represent the alternative set, let $C=$ $\left\{c_{1}, c_{2}, \ldots, c_{n}\right\}$ represent the attribute set, let $s=\left(s_{1}, s_{2}, \ldots, s_{n}\right)$ represent the attribute significance coefficient with $0 \leq s_{j} \leq$ 1 and $\sum_{j=1}^{n} s_{j}=1$, let $M=\left\{m_{1}, m_{2}, \ldots, m_{h}\right\}$ represent the decision-maker set, let $T=\left\{t_{1}, t_{2}, \ldots, t_{h}\right\}$ represent the period set, let $k=\left(k_{1}, k_{2}, \ldots, k_{h}\right)$ represent the period significance coefficients with $0 \leq k_{l} \leq 1$ and $\sum_{l=1}^{h} k_{l}=1$, let $\widetilde{V}^{(l)}=\left(\widetilde{v}_{i j}^{(l)}\right)_{m \times n}$ represent the initial decision matrix in period $t_{l}$, and let $\widetilde{v}_{i j}^{(l)}$ represent the alternative $a_{i}$ evaluation value under the attribute $c_{j}$ in period $t_{l}, \widetilde{v}_{i j}^{(l)}=\left(\widetilde{v}_{i j}^{(l), L}, \widetilde{v}_{i j}^{(l), M}, \widetilde{v}_{i j}^{(l), U}\right)$.

\subsection{The Decision-Making Method}

Step 1 (determine the period significance coefficients). Usually, the nearer the period approaches the decision point, the more important the period will be, and its significance coefficients should be bigger. In addition, there are some fluctuations in the decision-making environment caused by the uncertainty of the information and the vagueness of the human thinking. In order to obtain the stable period significance coefficients, the two factors mentioned above should be comprehensively considered in the process of the period significance coefficients optimal model construction. Suppose $\delta=\sum_{l=1}^{h}((h-l) /(h-1)) k_{l}$; then $\delta$ is called the time degree. The smaller $\delta$ is, the more important information closer to the decision point will be. The stable period significance coefficients can be calculated based on the value of $\delta$ and the distances of alternatives' evaluation value in different periods.

The sum of distances among alternatives' evaluation values in period $t_{l}$ can be computed

$$
d_{l}=\sum_{i=1}^{m} \sum_{k=1}^{m} \sum_{j=1}^{n} d\left(\widetilde{v}_{i j}^{(l)}, \widetilde{v}_{k j}^{(l)}\right) .
$$

The volatility of decision environment can be measured by variance:

$$
\begin{aligned}
D^{2}\left(d_{l} k_{l}\right) & =\sum_{l=1}^{h}\left[\left(d_{l} k_{l}-E\left(d_{l} k_{l}\right)\right)\right]^{2} \\
& =\frac{1}{h} \sum_{l=1}^{h}\left(d_{l} k_{l}\right)^{2}-\frac{1}{h^{2}}\left(\sum_{l=1}^{h} d_{l} k_{l}\right)^{2} .
\end{aligned}
$$


In order to obtain the stable period significance coefficients, the period significance coefficients optimal model is constructed as follows:

$$
\begin{array}{ll}
\min & Z=D^{2}\left(d_{l} k_{l}\right) \\
\text { s.t. } & \delta=\sum_{l=1}^{h} \frac{h-l}{h-1} k_{l} ; \\
& \sum_{l=1}^{h} k_{l}=1, \quad k_{l} \in[0,1], \quad l=1,2, \ldots, h .
\end{array}
$$

The decision information in different periods is integrated according to the period significance coefficients, and the comprehensive evaluation matrix $\widetilde{V}$ is obtained, $\widetilde{V}=$ $\left(\widetilde{v}_{i j}\right)_{m \times n}, \widetilde{v}_{i j}=\left(v_{i j}^{L}, v_{i j}^{M}, v_{i j}^{U}\right)$.

Step 2 (normalize the decision matrix). The decision matrix $\widetilde{V}=\left(\widetilde{v}_{i j}\right)_{m \times n}$ should be normalized according to the following equations [30]:

$$
\begin{aligned}
& v_{i j}^{*, L}=\frac{v_{i j}^{L}}{\sqrt{(1 / 3) \sum_{i=1}^{m}\left[\left(v_{i j}^{L}\right)^{2}+\left(v_{i j}^{M}\right)^{2}+\left(v_{i j}^{U}\right)^{2}\right]}}, \\
& v_{i j}^{*, M}=\frac{v_{i j}^{M}}{\sqrt{(1 / 3) \sum_{i=1}^{m}\left[\left(v_{i j}^{L}\right)^{2}+\left(v_{i j}^{M}\right)^{2}+\left(v_{i j}^{U}\right)^{2}\right]}}, \\
& v_{i j}^{*, U}=\frac{v_{i j}^{U}}{\sqrt{(1 / 3) \sum_{i=1}^{m}\left[\left(v_{i j}^{L}\right)^{2}+\left(v_{i j}^{M}\right)^{2}+\left(v_{i j}^{U}\right)^{2}\right]}},
\end{aligned}
$$

where $\widetilde{v}_{i j}^{*}=\left(v_{i j}^{*, L}, v_{i j}^{*, M}, v_{i j}^{*, U}\right)$ is the normalized form of $\widetilde{v}_{i j}=$ $\left(v_{i j}^{L}, v_{i j}^{M}, v_{i j}^{U}\right), 0 \leq v_{i j}^{*, L} \leq v_{i j}^{*, M} \leq v_{i j}^{*, U} \leq 1$.

Step 3 (calculate the attribute significance coefficients). The attribute significance coefficients are used to represent the importance of the attribute, which can be calculated by the maximum deviation method. The bigger the deviation of the attribute value is, the bigger the attribute significance coefficient will be. The attribute significance coefficients can be computed by the following equation:

$$
s_{j}=\frac{\sum_{i=1}^{m} \sum_{k=1}^{m} d\left(\widetilde{v}_{i j}^{*}, \widetilde{v}_{k j}^{*}\right)}{\sum_{j=1}^{n} \sum_{i=1}^{m} \sum_{k=1}^{m} d\left(\widetilde{v}_{i j}^{*}, \widetilde{v}_{k j}^{*}\right)},
$$

where $d\left(\widetilde{v}_{i j}^{*}, \widetilde{v}_{k j}^{*}\right)$ represents the distance between alternatives $a_{i}$ and $a_{k}$ under attribute $c_{j}$.

Step 4 (the triangular fuzzy MULTIMOORA method).

Step 4.1 (the triangular fuzzy ratio system method). The evaluation values of alternatives under the triangular fuzzy ratio system method can be obtained according to (19). Hence,

$$
\widetilde{Y}_{i}=\sum_{j=1}^{g} s_{j} \widetilde{v}_{i j}^{*}-\sum_{j=g+1}^{n} s_{j} \widetilde{v}_{i j}^{*}
$$

in which $\widetilde{Y}_{i}$ represents the evaluation value of alternative $a_{i}$, $\tilde{Y}_{i}=\left(Y_{i}^{L}, Y_{i}^{M}, Y_{i}^{U}\right), g$ and $n-g$ represent the numbers of benefit attributes and cost attributes, respectively. The bigger $\widetilde{Y}_{i}$ is, the better alternative $a_{i}$ will be.

The optimal alternative in the triangular fuzzy ratio system method can be obtained by (20). Hence,

$$
a_{\mathrm{TRS}}^{*}=\left\{a_{i} \mid \max _{i} \widetilde{Y}_{i}\right\} \text {. }
$$

Step 4.2 (the triangular fuzzy reference point method). The reference point of the $j$ th attribute can be determined according to (21). Hence,

$$
\tilde{r}_{j}= \begin{cases}\tilde{r}_{j}^{+}=\max _{i} \widetilde{v}_{i j}^{*}, & j \leq g, \\ \tilde{r}_{j}^{-}=\min _{i} \widetilde{v}_{i j}^{*}, & j>g .\end{cases}
$$

The deviation between $\widetilde{v}_{i j}^{*}$ and $\widetilde{r}_{j}$ can be defined as follows:

$$
d_{i j}=d\left(s_{j} \widetilde{r}_{j}, s_{j} \widetilde{v}_{i j}^{*}\right) \text {. }
$$

Based on this, the evaluation values of alternatives under the triangular fuzzy reference point method can be calculated as the following equation:

$$
Z_{i}=\max _{j} d_{i j}=\max _{j}\left\{d\left(s_{j} \widetilde{r}_{j}, s_{j} \widetilde{v}_{i j}^{*}\right)\right\} .
$$

According to (9), the smaller $Z_{i}$ is, the better alternative $a_{i}$ will be. The optimal alternative under the triangular fuzzy reference point method can be determined by the following equation:

$$
a_{\mathrm{TRP}}^{*}=\left\{a_{i} \mid \min _{i} Z_{i}\right\}
$$

Step 4.3 (the triangular fuzzy full multiplicative form method). The evaluation values of alternatives under the triangular fuzzy full multiplicative form method can be computed according to (25). Hence,

$$
\widetilde{U}_{i}=\frac{\prod_{j=1}^{g}\left(\widetilde{v}_{i j}^{*}\right)^{s_{j}}}{\prod_{j=g+1}^{n}\left(\widetilde{v}_{i j}^{*}\right)^{s_{j}}},
$$

where $\widetilde{U}_{i}$ represents the evaluation value of the alternative $a_{i}$. The bigger $\widetilde{U}_{i}$ is, the better alternative $a_{i}$ will be. Hence, the optimal alternative under the triangular fuzzy full multiplicative form method can be determined by the following equation:

$$
a_{\mathrm{TMF}}^{*}=\left\{a_{i} \mid \max _{i} \widetilde{U}_{i}\right\}
$$


TABLE 1: The decision matrixes in different periods.

\begin{tabular}{ccccc}
\hline & & $c_{1}$ & $c_{2}$ & $c_{3}$ \\
\hline \multirow{4}{*}{$\widetilde{V}^{(1)}$} & $a_{1}$ & {$[5.4,6.2,7.8]$} & {$[7.5,8.6,9.2]$} & {$[4.3,4.6,5.2]$} \\
& $a_{2}$ & {$[6.2,7.1,8.2]$} & {$[6.9,7.5,8.8]$} & {$[3.8,4.5,5.1]$} \\
& $a_{3}$ & {$[6.9,7.6,8.8]$} & {$[7.3,8.8,9.5]$} & {$[4.3,4.7,5.7]$} \\
& $a_{4}$ & {$[6.6,7.5,8.9]$} & {$[6.6,7.5,8.4]$} & {$[4.2,4.8,5.6]$} \\
\hline \multirow{4}{*}{$\widetilde{V}^{(2)}$} & $a_{1}$ & {$[6.4,7.3,8.5]$} & {$[7.3,8.4,9.1]$} & {$[3.7,4.4,4.9]$} \\
& $a_{2}$ & {$[6.5,7.0,8.4]$} & {$[6.5,7.3,8.5]$} & {$[3.5,4.1,4.7]$} \\
& $a_{3}$ & {$[5.8,6.5,7.8]$} & {$[7.3,8.5,9.3]$} & {$[4.3,4.6,4.9]$} \\
& $a_{4}$ & {$[7.6,8.3,9.4]$} & {$[6.7,7.5,8.3]$} & {$[4.5,4.7,5.2]$} \\
\hline & $a_{1}$ & {$[5.4,6.2,7.8]$} & {$[6.5,7.6,8.2]$} & {$[4.3,5.1,5.8]$} \\
$\widetilde{V}^{(3)}$ & $a_{2}$ & {$[6.2,7.1,8.2]$} & {$[5.9,7.3,8.1]$} & {$[4.1,4.8,5.5]$} \\
& $a_{3}$ & {$[6.9,7.6,8.8]$} & {$[8.0,8.8,9.5]$} & {$[4.6,5.4,5.9]$} \\
& $a_{4}$ & {$[6.6,7.5,8.9]$} & {$[6.3,7.5,8.9]$} & {$[4.5,3.0,6.2]$} \\
\hline
\end{tabular}

TABLE 2: The comprehensive decision matrix $\widetilde{V}$.

\begin{tabular}{ccccc}
\hline & & $c_{1}$ & $c_{2}$ & $c_{3}$ \\
\hline & $a_{1}$ & {$[5.8,6.6,8.0]$} & {$[6.9,8.0,8.6]$} & {$[4.1,4.8,5.4]$} \\
$\widetilde{V}$ & $a_{2}$ & {$[6.3,7.1,8.3]$} & {$[6.2,7.3,8.3]$} & {$[3.8,4.5,5.2]$} \\
& $a_{3}$ & {$[6.5,7.2,8.4]$} & {$[7.7,8.7,9.4]$} & {$[4.5,5.0,5.5]$} \\
& $a_{4}$ & {$[7.0,7.8,9.1]$} & {$[6.5,7.5,8.6]$} & {$[4.5,5.0,5.8]$} \\
\hline
\end{tabular}

Step 5 (the final ranking of alternatives). The alternative rankings obtained from Steps 4.1, 4.2, and 4.3 can be integrated into the final ranking of alternatives according to the dominance theory.

\section{Numerical Example}

An investment company intends to choose and invest the best one from four alternatives. In order to obtain the reasonable result, 5 experts are invited to evaluate alternatives from the economic benefits, the social benefits, and the environment pollution. Let $A=\left\{a_{1}, a_{2}, a_{3}, a_{4}\right\}$ represent the alternative set, let $C=\left\{c_{1}, c_{2}, c_{3}\right\}$ represent the attribute set $\left(c_{1}\right.$ and $c_{2}$ are the benefit attributes; $c_{3}$ is the cost attribute), let $T=$ $\left\{t_{1}, t_{2}, \ldots, t_{h}\right\}$ represent the period set, let $s=\left(s_{1}, s_{2}, \ldots, s_{n}\right)$ represent the attribute significance coefficients with $0 \leq s_{j} \leq$ 1 and $\sum_{j=1}^{n} s_{j}=1$, let $k=\left(k_{1}, k_{2}, \ldots, k_{h}\right)$ represent the period significance coefficients with $0 \leq k_{j} \leq 1$ and $\sum_{j=1}^{n} k_{j}=1$, let $\widetilde{V}^{(l)}=\left(\widetilde{v}_{i j}^{(l)}\right)_{m \times n}$ represent the decision matrix in period $t_{l}$, and let $\widetilde{v}_{i j}^{(l)}$ represent the evaluation value of alternative $a_{i}$ under attribute $c_{j}$ in period $t_{l}, \widetilde{v}_{i j}^{(l)}=\left(\widetilde{v}_{i j}^{(l), L}, \widetilde{v}_{i j}^{(l), M}, \widetilde{v}_{i j}^{(l), U}\right)$. The decision matrixes in different periods are constructed according to the evaluation values given by each expert; the results are shown in Table 1.

Step 1 (determine the period significance coefficients). The distances among alternatives in different periods can be calculated by (12): $d_{1}=1.522, d_{2}=1.786$, and $d_{3}=1.747$.
Let $\delta$ be 0.3 according to decision-makers' experience. Based on this, the period significance coefficients optimal model is constructed by (14). Hence,

$\min Z$

$$
\begin{gathered}
=\frac{\left(\left(1.522 k_{1}\right)^{2}+\left(1.786 k_{2}\right)^{2}+\left(1.747 k_{3}\right)^{2}\right)}{3} \\
-\frac{\left(1.522 k_{1}+1.786 k_{2}+1.747 k_{3}\right)^{2}}{9}
\end{gathered}
$$

s.t. $\quad k_{1}+\frac{1}{2} k_{2}=0.3$

$$
\sum_{l=1}^{3} k_{l}=1, \quad k_{l} \in[0,1], l=1,2,3 .
$$

The period significance coefficients can be computed using lingo 11.0: $k_{1}=0.122, k_{2}=0.356$, and $k_{3}=0.522$. Based on this, the comprehensive decision matrix $\bar{V}$ is obtained by aggregating the evaluation values of alternatives in different periods; the results are shown in Table 2.

Step 2 (normalize the comprehensive decision matrix). The comprehensive decision matrix $\bar{V}$ can be normalized to $\bar{V}^{*}$ according to (15) (17); the results are shown in Table 3 .

Step 3 (determine the attribute significance coefficients). According to (18), the attribute significance coefficients are $s=(0.335,0.374,0.291)$. 
TABLE 3: The normalized comprehensive decision matrix $\widetilde{V}^{*}$.

\begin{tabular}{ccccc}
\hline & & $c_{1}$ & $c_{2}$ & $\mathcal{c}_{3}$ \\
\hline & $a_{1}$ & {$[0.388,0.445,0.543]$} & {$[0.438,0.508,0.548]$} & {$[0.419,0.491,0.554]$} \\
$\bar{V}^{*}$ & $a_{2}$ & {$[0.426,0.477,0.558]$} & {$[0.395,0.465,0.528]$} & {$[0.395,0.463,0.530]$} \\
& $a_{3}$ & {$[0.440,0.487,0.571]$} & {$[0.487,0.552,0.598]$} & {$[0.458,0.516,0.566]$} \\
& $a_{4}$ & {$[0.469,0.525,0.613]$} & {$[0.411,0.476,0.548]$} & {$[0.460,0.516,0.591]$} \\
\hline
\end{tabular}

TABLE 4: The results of the triangular fuzzy ratio system method.

\begin{tabular}{cccc}
\hline & $\widetilde{Y}_{i}$ & $Y_{i}$ & Ranking \\
\hline$a_{1}$ & {$[0.172,0.196,0.226]$} & 0.197 & 4 \\
$a_{2}$ & {$[0.176,0.199,0.231]$} & 0.201 & 3 \\
$a_{3}$ & {$[0.196,0.220,0.250]$} & 0.221 & 1 \\
$a_{4}$ & {$[0.177,0.204,0.238]$} & 0.206 & 2 \\
\hline
\end{tabular}

TABLE 5: The results of the triangular fuzzy reference point method.

\begin{tabular}{|c|c|c|c|c|c|}
\hline \multicolumn{4}{|c|}{$\begin{array}{l}\text { Distances between } \\
\text { the attribute values } \\
\text { and the reference points }\end{array}$} & \multirow[t]{2}{*}{$Z_{i}$} & \multirow[t]{2}{*}{ Ranking } \\
\hline & $c_{1}$ & $c_{2}$ & $c_{3}$ & & \\
\hline$a_{1}$ & 0.026 & 0.018 & 0.008 & 0.026 & 3 \\
\hline$a_{2}$ & 0.016 & 0.031 & 0.000 & 0.031 & 4 \\
\hline$a_{3}$ & 0.012 & 0.000 & 0.015 & 0.015 & 1 \\
\hline$a_{4}$ & 0.000 & 0.026 & 0.017 & 0.026 & 2 \\
\hline
\end{tabular}

TABLE 6: The results of the triangular fuzzy full multiplicative form method.

\begin{tabular}{cccc}
\hline & $\widetilde{U}_{i}$ & $U_{i}$ & Ranking \\
\hline$a_{1}$ & {$[0.635,0.728,0.838]$} & 0.732 & 4 \\
$a_{2}$ & {$[0.639,0.733,0.849]$} & 0.739 & 3 \\
$a_{3}$ & {$[0.685,0.763,0.858]$} & 0.767 & 1 \\
$a_{4}$ & {$[0.648,0.740,0.849]$} & 0.745 & 2 \\
\hline
\end{tabular}

Step 4 (the triangular fuzzy MULTIMOORA method).

Step 4.1 (the triangular fuzzy ratio system method). The evaluation values and the ranking of alternatives under the triangular fuzzy ratio system method can be obtained by (19) and (20). The results are listed in Table 4.

Step 4.2 (the triangular fuzzy reference point method). The evaluation values and the ranking of alternatives under the triangular fuzzy reference point method can be obtained by (21) (24) and the results are listed in Table 5.

Step 4.3 (the triangular fuzzy full multiplicative form method). The evaluation values and the ranking of alternatives under the triangular fuzzy full multiplicative form method can be obtained according to (25) and (26) and the results are shown in Table 6.

Step 5 (the final ranking of alternatives). The rankings of alternatives obtained by Step 4 can be integrated into the final ranking by the dominance theory. The results are shown in Table 7.

Recently, many MADM methods are proposed to deal with the problem under the fuzzy environment. Liu [15] proposed an extension of the technique for order preference by similarity to ideal solution (TOPSIS) based on the triangular fuzzy number. Jiang [16] extended the VIsekriterijumska optimizacija i KOmpromisno Resenje (VIKOR) into the triangular fuzzy number environment. Chatterjee and Chakraborty [25] used the operational competitiveness rating analysis (OCRA), the preference ranking organization methods for enrichment evaluations (PROMETHEE), and F-TOPSIS to solve the material selection problem. In order to illustrate the effectiveness and feasibility of our proposed method, methods proposed by literatures $[15,16,25]$ are used to deal with the decision problem mentioned above. The results are listed in Table 8 .

All methods listed in Table 8 obtained $a_{4}$ as the optimal alternative, which proves our proposed method is effective and feasible.

\section{Conclusion}

In the practical decision-making, if decision-makers ignore the historical information of the decision object, they will not comprehensively describe the decision object and obtain reasonable results. However, most of the existing MAGDM methods only consider the current information of the decision object. Besides, decision-makers are difficult to give the crisp evaluation value because of the complexity of the decision environment and the fuzziness of human cognition. Aiming at these problems mentioned above, we put forward a novel extended method of MULTIMOORA to solve the MAGDM problem.

Compared with other existing MAGDM methods, the advantages of our proposed method are described as follows: (1) our proposed method considers the information of the decision object in different periods, so it can comprehensively describe the decision object and obtains more reasonable results; (2) in the process of constructing period significance coefficients optimization model, the information influence degree in different periods on the decision results and the volatility of the decision environment are considered, which will help to obtain more stable period significance coefficients; (3) triangular fuzzy numbers are used to represent the decision information, which not only can express the interval ranges of the decision information but also can highlight the gravity center having the largest probability. In addition, triangular fuzzy numbers can make up the deficiencies of 
TABLE 7: The final ranking of alternatives.

\begin{tabular}{|c|c|c|c|c|}
\hline & & Ranking & & \\
\hline & $\begin{array}{l}\text { The triangular fuzzy ratio system } \\
\text { method }\end{array}$ & $\begin{array}{l}\text { The triangular fuzzy reference point } \\
\text { method }\end{array}$ & $\begin{array}{l}\text { The triangular fuzzy full multiplicative } \\
\text { form method }\end{array}$ & $\begin{array}{l}\text { The final } \\
\text { ranking }\end{array}$ \\
\hline$a_{1}$ & 4 & 3 & 4 & 4 \\
\hline$a_{2}$ & 3 & 4 & 3 & 3 \\
\hline$a_{3}$ & 2 & 2 & 1 & 2 \\
\hline$a_{4}$ & 1 & 1 & 2 & 1 \\
\hline
\end{tabular}

TABLE 8: The comparisons between the proposed method and other methods.

\begin{tabular}{lcccccc}
\hline & & \multicolumn{3}{c}{ Ranking } \\
& The proposed method & TF-TOPSIS [15] & TF-VIKOR [16] & F-VIKOR [25] & PROMETHEE [25] & OCRA [25] \\
\hline$a_{1}$ & 4 & 4 & 4 & 4 & 3 \\
$a_{2}$ & 3 & 3 & 3 & 3 & 4 & 2 \\
$a_{3}$ & 2 & 2 & 2 & 2 & 2 \\
$a_{4}$ & 1 & 1 & 1 & 1 & 1 \\
\hline
\end{tabular}

the interval number in precision and facilitate the decisionmaking at least to some extent. In this paper, all significance coefficients are exact numbers. The future work of this paper is to discuss the significance coefficient being triangular fuzzy number form.

\section{Competing Interests}

There are no competing interests related to this paper.

\section{References}

[1] G.-W. Wei, "A method for multiple attribute group decision making based on the ET-WG and ET-OWG operators with 2tuple linguistic information," Expert Systems with Applications, vol. 37, no. 12, pp. 7895-7900, 2010.

[2] Y.-J. Xu and Q.-L. Da, "Standard and mean deviation methods for linguistic group decision making and their applications," Expert Systems with Applications, vol. 37, no. 8, pp. 5905-5912, 2010.

[3] Z. P. Chen and W. Yang, "An MAGDM based on constrained FAHP and FTOPSIS and its application to supplier selection," Mathematical and Computer Modelling, vol. 54, no. 11-12, pp. 2802-2815, 2011.

[4] G.-W. Wei, "Grey relational analysis method for 2-tuple linguistic multiple attribute group decision making with incomplete weight information," Expert Systems with Applications, vol. 38, no. 5, pp. 4824-4828, 2011.

[5] Z. S. Xu, "On method for uncertain multiple attribute decision making problems with uncertain multiplicative preference information on alternatives," Fuzzy Optimization and Decision Making, vol. 4, no. 2, pp. 131-139, 2005.

[6] Z. S. Xu, "Uncertain linguistic aggregation operators based approach to multiple attribute group decision making under uncertain linguistic environment," Information Sciences, vol. 168, no. 1-4, pp. 171-184, 2004.

[7] Z. S. Xu, "Approaches to multiple attribute group decision making based on intuitionistic fuzzy power aggregation operators," Knowledge-Based Systems, vol. 24, no. 6, pp. 749-760, 2011.
[8] S.-J. Chuu, "Interactive group decision-making using a fuzzy linguistic approach for evaluating the flexibility in a supply chain," European Journal of Operational Research, vol. 213, no. 1, pp. 279-289, 2011.

[9] S.-M. Chen and S.-J. Niou, "Fuzzy multiple attributes group decision-making based on fuzzy preference relations," Expert Systems with Applications, vol. 38, no. 4, pp. 3865-3872, 2011.

[10] Q.-W. Cao and J. Wu, “The extended COWG operators and their application to multiple attributive group decision making problems with interval numbers," Applied Mathematical Modelling, vol. 35, no. 5, pp. 2075-2086, 2011.

[11] T. Baležentis and S. Zeng, "Group multi-criteria decision making based upon interval-valued fuzzy numbers: an extension of the MULTIMOORA method," Expert Systems with Applications, vol. 40, no. 2, pp. 543-550, 2013.

[12] D. Stanujkic, N. Magdalinovic, R. Jovanovic, and S. Stojanovic, "An objective multi-criteria approach to optimization using MOORA method and interval grey numbers," Technological and Economic Development of Economy, vol. 18, no. 2, pp. 331-363, 2012.

[13] M. Dong, S. Li, and H. Zhang, "Approaches to group decision making with incomplete information based on power geometric operators and triangular fuzzy AHP," Expert Systems with Applications, vol. 42, no. 21, pp. 7846-7857, 2015.

[14] Ö. Aydin, "Bulanik AHP ile Ankara için hastane yer seçimi," Journal of Dokuz Eylul University Faculty of Economics and Administrative Sciences, vol. 24, no. 2, pp. 87-104, 2009.

[15] W.-S. Liu, "Research on preferred method of connection mining village based on AHP-TOPSIS of triangular fuzzy numbers," Application Research of Computers, vol. 33, no. 2, pp. 458-462, 2016.

[16] W.-Q. Jiang, "Extension of VIKOR method for multi-criteria group decision making problems with triangular fuzzy numbers," Control and Decision, vol. 30, no. 6, pp. 1059-1064, 2015.

[17] W. K. M. Brauers and E. K. Zavadskas, "The MOORA method and its application to privatization in a transition economy," Control and Cybernetics, vol. 35, no. 2, pp. 445-469, 2006.

[18] P. Karande and S. Chakraborty, "Application of multi-objective optimization on the basis of ratio analysis (MOORA) method 
for materials selection," Materials \& Design, vol. 37, pp. 317-324, 2012.

[19] W. K. M. Brauers, A. Baležentis, and T. Baležentis, "Multimoora for the EU member States updated with fuzzy number theory," Technological and Economic Development of Economy, vol. 17, no. 2, pp. 259-290, 2011.

[20] W. K. M. Brauers and E. K. Zavadskas, "Project management by MULTIMOORA as an instrument for transition economies," Technological and Economic Development of Economy, vol. 16, no. 1, pp. 5-24, 2010.

[21] W. K. M. Brauers and E. K. Zavadskas, "Multimoora optimization used to decide on a bank loan to buy property," Technological and Economic Development of Economy, vol. 17, no. 1, pp. 174-188, 2011.

[22] A. Hafezalkotob and A. Hafezalkotob, "Comprehensive MULTIMOORA method with target-based attributes and integrated significant coefficients for materials selection in biomedical applications," Materials and Design, vol. 87, pp. 949-959, 2015.

[23] W. K. M. Brauers and E. K. Zavadskas, "Robustness of MULTIMOORA: a method for multi-objective optimization," Informatica, vol. 23, no. 1, pp. 1-25, 2012.

[24] R. R. Yager, "On ordered weighted averaging aggregation operators in multicriteria decisionmaking," IEEE Transactions on Systems, Man, and Cybernetics, vol. 18, no. 1, pp. 183-190, 1988.

[25] P. Chatterjee and S. Chakraborty, "Material selection using preferential ranking methods," Materials and Design, vol. 35, pp. 384-393, 2012.

[26] H.-C. Liu, X.-J. Fan, P. Li, and Y.-Z. Chen, "Evaluating the risk of failure modes with extended MULTIMOORA method under fuzzy environment," Engineering Applications of Artificial Intelligence, vol. 34, pp. 168-177, 2014.

[27] A. Baležentis, T. Baležentis, and W. K. M. Brauers, "Personnel selection based on computing with words and fuzzy MULTIMOORA," Expert Systems with Applications, vol. 39, no. 9, pp. 7961-7967, 2012.

[28] S. Datta, N. Sahu, and S. Mahapatra, "Robot selection based on grey-MULTIMOORA approach," Grey Systems: Theory and Application, vol. 3, no. 2, pp. 201-232, 2013.

[29] G. S. Liang and J. F. Ding, "Fuzzy MCDM based on the concept of $\alpha$-cut," Journal of Multi-Criteria Decision Analysis, vol. 12, no. 6, pp. 299-310, 2003.

[30] J. M. Merigó and M. Casanovas, "Induced and uncertain heavy OWA operators," Computers and Industrial Engineering, vol. 60, no. 1, pp. 106-116, 2011. 


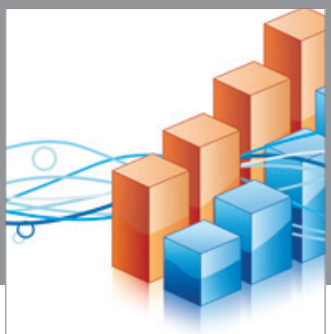

Advances in

Operations Research

vatem alat4

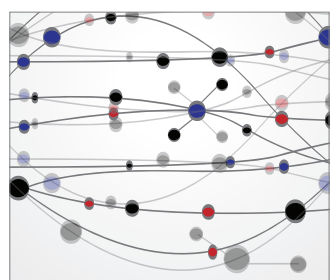

\section{The Scientific} World Journal
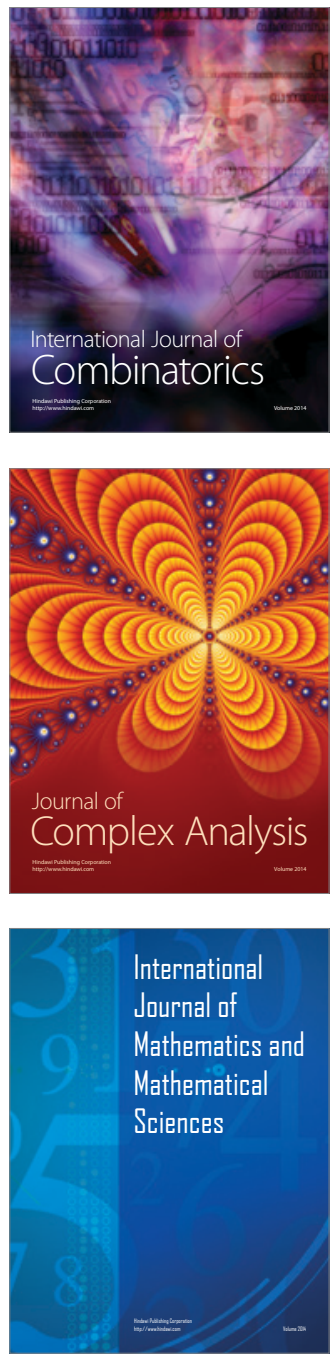
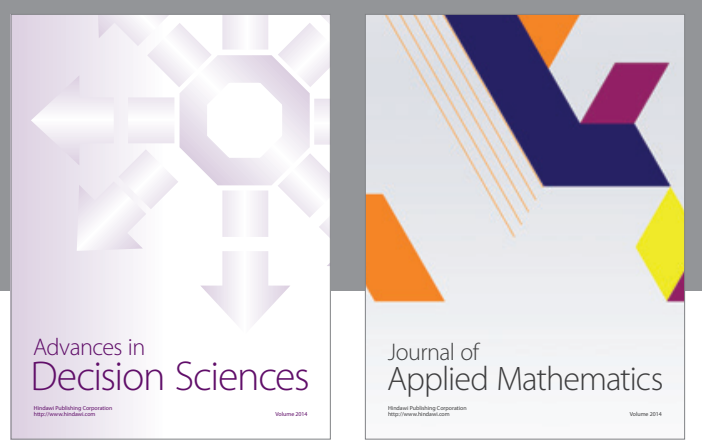

Algebra

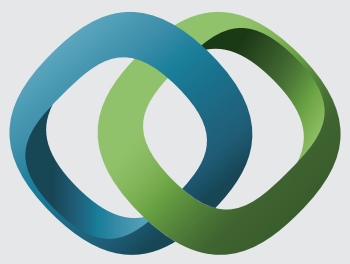

\section{Hindawi}

Submit your manuscripts at

http://www.hindawi.com
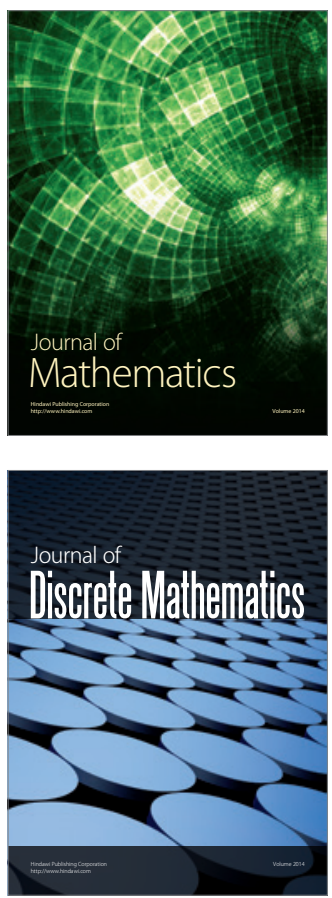

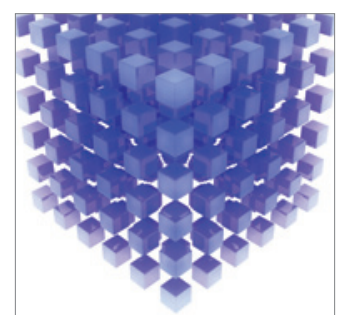

Mathematical Problems in Engineering
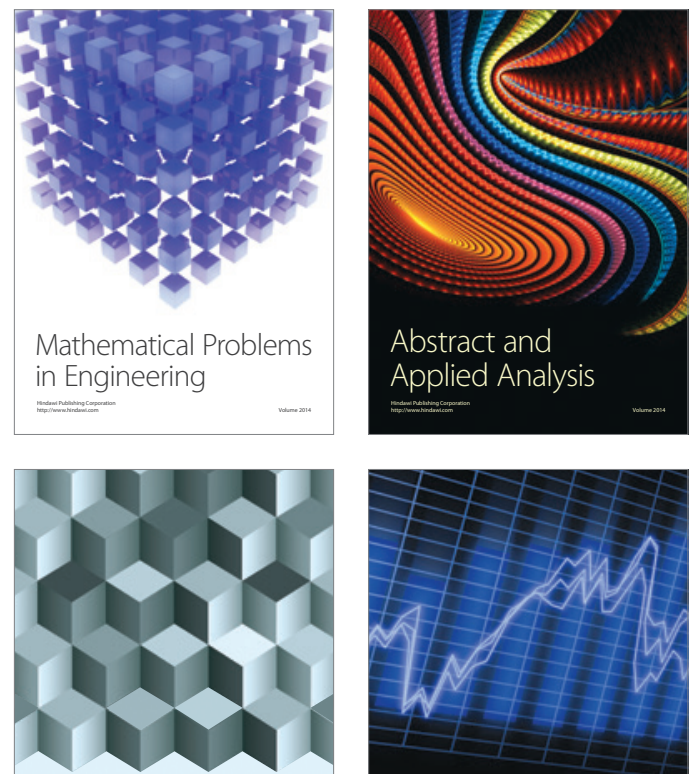

Journal of

Function Spaces

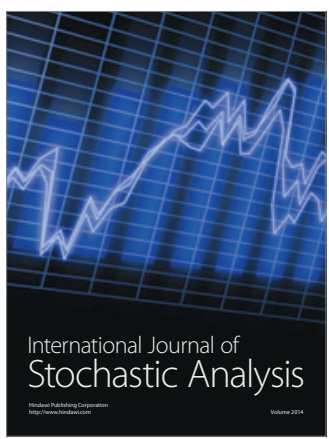

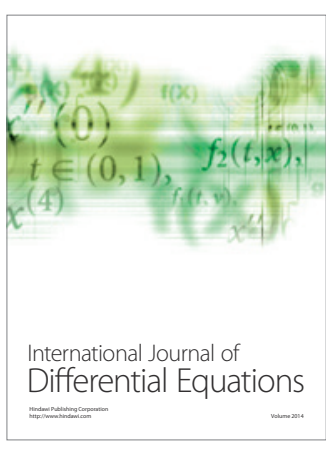
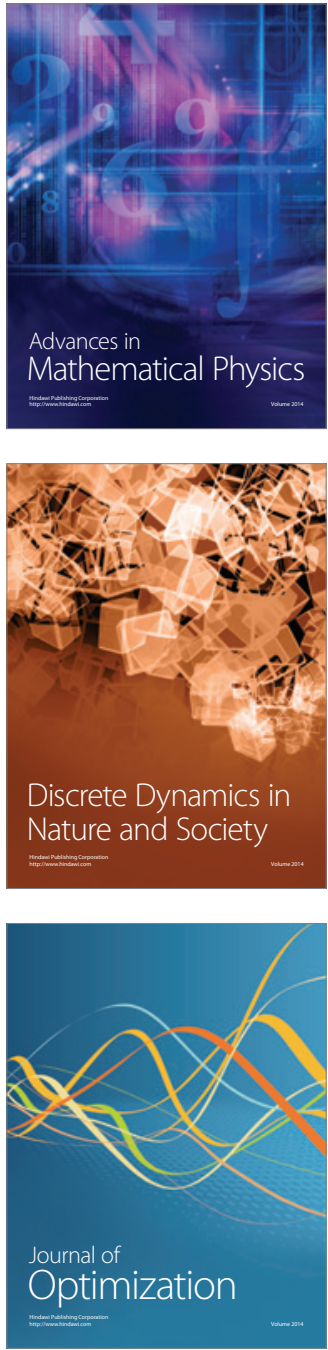